\title{
Topographic recording of the Slalom racing route in snow
}

\author{
Giovanis V.F.ABCDE, Yiaghis F.A. ${ }^{\text {BDE }}$, Vasileiou P.V. ${ }^{\text {DE }}$ \\ School of Physical Education and Sport Science, National and Kapodistrian University of Athens, Greece
}

Authors' Contribution:

A - Study design; B - Data collection; C - Statistical analysis; D - Manuscript Preparation; E - Funds Collection.

\begin{abstract}
Purpose: $\quad$ The purpose of the present research was the study and evaluation of the theodolite's (topographic speedometer) use in tracing a path in slalom racing on snow conditions with 58 gates and also to record the optimal method of tracing a slalom route in relation to: a) the "velocity" of the race track (degree of difficulty of slalom), b) safety of tracing the slalom route.

Material: $\quad$ This research was based on methodology and measurements of a race track in giant slalom with 35 gates in the ski resort "3-5 Pigadia" of Naoussa - Greece. The topographic speedometer was fixed in place at the start of the route. From this point, measurements were taken, for the placement of all 58 gates throughout the route. The measurement was taken using the pole-prism, placed in each interior gate turn, at which the theodolite was aimed. With the help of topographic speedometer the following geometrical parameters have been registered: distance between the gates $(\Delta s)$, altitude difference of points $(\Delta \mathrm{h})$ with an accuracy up to $1 \mathrm{~cm}$, terrain slope $(\theta)$, gate angular deviation $(\delta)$ with an accuracy of up to 1 minute of the angle $\left({ }^{\circ}\right)$. This allows the creation of the top-view, side-view (profile) and three-dimensional aspect of the track, under race conditions on snow and not on dry ground.

Results: $\quad$ The correlation coefficient ( $r$ ) between the geometry factor (V.gs) and average the above geometry parameters had the following respective values: V.gs $-M s=0,15$, V.gs $-M \theta=-0,52$, V.gs $-M \delta=-0,29$ for 58 gates on a level of statistical significance of $p<0,05$.

Conclusions: The first part comprised of 10 gates was the "fastest" (V.gs $=18$ degrees) of the total slalom route in Naoussa with 58 gates (V.gs = 14 degrees). With the above criteria, slaloms will be compared to each other and will be evaluated against age and safety.

Keywords: Topographic speedometer, slalom racing route, geometry, velocity of slalom
\end{abstract}

\section{Introduction}

Nowadays, the constant pressure to increase the quality of competition and entertainment in sports, have led to the effort of finding new means in order to improve the execution of such sports. Likewise in alpine skiing, optimal conditions are necessary to conduct a slalom race with the best possible results and spectacle. The above can be achieved by designing and tracing a slalom course as early as possible before the start of a race. The above preparation is done to avoid any climate change, which can affect the quality and safety of the track and the quality of the athlete's descent. Appropriate instruments need to be used for this purpose, such as the topographic speedometer (theodolite) in the route tracing.

The International Ski Federation (FIS) implements the "topographic speedometer" for the topographic recording of race route in dry ground without snow and without gates, with purpose of homologating the route for ski season. The homologated route is presented in races and includes the following general geometry parameters: the length and the width of the route, the height difference and the terrain slope at about every 100 -150 meters from start to finish [1].

In the 1980s, researchers applied the passage analysis of athletes only on some gates of the Alpine skiing route [2-4]. In the 1990s, the process of passing the athletes was investigated all the way through the giant slalom Alpine skiing in 35 gates [5-7]. The aim of the research was to measure the distances, the altitude difference and

(C) Giovanis V.F., Yiaghis F.A., Vasileiou P.V., 2018

doi:10.15561/18189172.2018.0101 the slope of the ground between the gates, as well as the angular deviation (deviation) of the route between the gates (right-left). After 2000, alpine skiing events outside the slalom continued with various methods, eg. [8-11], using a special satellite system method [12-15], using a three-dimensional analysis method [16-18]. Models of race route geometry were dealt with by the following researchers: [19-21], while the longitudinal development of topographic analysis was studied by [22-25].

For the research completion, the following incentives have been examined:

1) Acquisition of comparative information in modern topographic measurements on ski route compared to conventional methods.

2) Verification of the topographical speedometer's (theodolite) significance.

3) Diffusion of the topographic speedometer on a larger scale.

The purpose of the present research was the study and evaluation of the theodolite's use in tracing a path in slalom racing on snow conditions with 58 gates and also to record the optimal method of tracing a slalom route in relation to: a) the "velocity" (V.gs) of the racetrack (degree slalom route difficulty), b) tracking security in the slalom route.

a. The term "velocity" of the race track means that the largest value (degree) of the coefficient of slalom's geometry (V.gs) will characterize a more rapid slalom (or section between gates) and consequently a possibility for a higher average speed. With this criteria, a comparison between slaloms can be made and. This evaluation will be 
made in relation to age group and safety.

b. Safety of tracing the slalom, means applying the regulations of the race, the determined angles the course inclination and the deviatiom of the gates as well as the specified length of segments between each gate. The above data (side-view, top-view and three-dimensional form of slalom) have to be printed and distributed in time before the race, so that the descent of most athletes will be safe and effective.

Research questions and statistical hypotheses

The experience and the results of the other research are the basis for the following research questions:

1) What is the relationship between the topographic speedometer and the morphology of the race track (the slope of the route, the quality of the snow, and the total number of turns of the route from start to finish)?

2) Is it feasible to give the analytical tracing plan of the route (route mapping) one hour before the race (the map with the side-view, the top-view and the threedimensional form of slalom)? Obviously the route from the day before causes alterations during the night.

3) How much does the topographic speedometer influence in the route engraving?

\section{Prerequisites}

The morphology of the terrain is determined by factors such as: slope of the route, width of the route, weather conditions such as: wind, sun (temperature), moisture (fog), snowfall or snow type [26, 27]. The type and the quality of snow also depend substantially on the time of the day in which the evaluation is made.

\section{Material and methods}

Participants. The research was based on the methodology and measurements of the giant slalom race track with 35 gates in the ski center 'Tria - Pente Pigadia" of Naoussa-Greece [6]. In the present study, the topographic speedometer (theodolite), which was permanently placed next to the start of the route, was used. From this point on, the 58 gates slalom measurements were made all the way to the finish. The measurements have been made in the ski center ''Tria - Pente Pigadia" of Naoussa-Greece.

\section{Research Design.}

The characteristics of the topographic speedometer

The topographic speedometer is an instrument used primarily by engineer surveyors to measure areas and distances. Measurements and topographical plans of a slalom route would not be so analytically measured without surveying instruments, thus saving time and energy. The instrument consists of three parts (Figure 1): the base, which is a tripod, the unit, placed on top of the tripod and the pole, with a prism that serves in more accurate measurements of long distances.

The function of the topographic speedometer consists of a beam of light-laser that is projected from the instrument to a desired target point or object, (prism-pole) that reflects on the prism and returns to the instrument. This is how the distance between the desired spots is measured. It also collects information such as the height difference of the points or their inclination, either in relation with the instrument or in relation to each other points.

Determination of the geometrical parameters of the race track.

The aforementioned instrument was placed at a fixed spot at the start of the route. From this point, measurements were made for the placement of the 58 gates throughout the 59 sections route (the starting gate was number zero). The measurement was made throughout the whole route with the pole-prism being placed each time at the desired point and the beam being targeted towards the prism.

The following geometric parameters have been

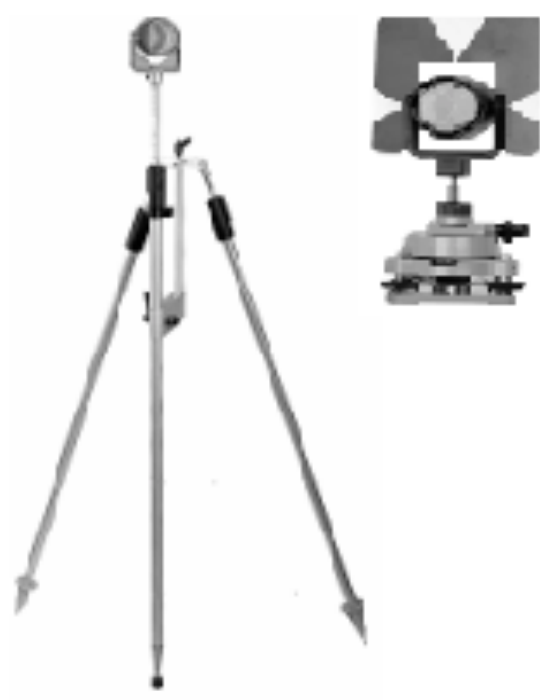

b)

Figure 1. The instruments of measurement of the geometry parameters: a) the topographic speedometer b) Pole and prism (Stonex-manual). 
recorded (Table 1): distance between each gate $(\Delta s)$, altitude difference of points $(\Delta \mathrm{h})$ and terrain slope $(\theta)$, angular positioning (deviation) of the gates of slalom $(\delta)$. The deviation angle values were achieved by the subtraction of angles as follows: $\delta . i=\gamma . i-180^{\circ}$ (the angles have been measured by the topographic speedometer in relation to the north direction - Figure 2-5). The above geometric parameters allow the creation of side-view, top-view and the three -dimensional form of the route [6].

Determination of slalom geometry factor:

The slalom geometry coefficient may be used for the collective interpretation of the basic data in slalom in the route engraving, relative to the passage speed of the route. The quality characteristic used in interpreting the word "speed" can be replaced with a quantitative trait, by using the values of the slalom geometry coefficient [6]:

$$
\mathrm{V} . \mathrm{gs}=[\mathrm{Ms} /(\mathrm{M} \theta \mathrm{x} \mathrm{M} \delta)] \times 1000
$$

where:

V.gs - slalom geometry factor,

Ms - average value of length of the segments between gates,

$\mathrm{M} \theta$ - average value of the slope angle,

$\mathrm{M} \delta$ - average value of the deviation angle of the route.

Note: the highest value of the coefficient V.gs will characterize the most "speed" slalom or a section between the gates, thus allowing a greater athletes' average speed. On this basis a comparability among different slaloms will be possible and also an evaluation in relation to safety.

\section{Statistical analysis}

In the slalom race route the values were read via theodolite, where the angles $(\theta \& \delta)$ had an accuracy of less than 1 degree, up to one minute of angle, while the measurement of the distance (s) was made with an accuracy of up to $1 \mathrm{~cm}$. Data concerning the material and the results of the research have been acquired with standard statistical analysis using the program Excel 7, while Figures have been created using the program Auto Cad. All material of geometrical parameters and the coefficients of slalom were measured using the following data statistics: the average value $(\mathrm{M})$, the standard deviation (SD) and the coefficient of variation (V). The above data were recorded in the work protocol (Table 1) for the first 10 gates and the entire slalom route (58 gates).

\section{Results}

Geometry parameters of the slalom path

The aggregating results of the geometrical parameters of the slalom in Naoussa are presented in Table 1, while Figures 2, 3 and 4 respectively show the side-view, topview and the three-dimensional form of the race track. The distances between the turning gates vary from 0,73 $\mathrm{m}$ to $17,61 \mathrm{~m}$, where the average value was $8,81 \mathrm{~m} \pm$ 3,13 . The total distance from start to finish was $519,86 \mathrm{~m}$. The height difference between gates ranged from $0,01 \mathrm{~m}$ to $5,68 \mathrm{~m}$, while the total difference in altitude between the start and finish was $178,26 \mathrm{~m}$. The largest terrain slope value, appeared at the beginning of the last part of the route $32^{\circ}(62 \%)$, while the smallest terrain slope value appeared at the end of the last part $1^{\circ}(2 \%)$. The average value of the terrain slope of the slalom was $19,97^{\circ}$ $(36.51 \%)$ with a typical deviation of $\pm 5,97^{\circ}(11,42 \%)$. The course deviation angles ranged from $4,4^{\circ}$ to $88,1^{\circ}$, where the average price was $30,72^{\circ} \pm 18,81^{\circ}$.

Slalom geometrical coefficient

Table 1. The aggregated results of the parameters and the coefficients of geometry of slalom in Naoussa in 10 gates and 58 gates: $\mathrm{h}$ - height from the finish line, $\Delta \mathrm{h}$ - altitude difference, $\mathrm{s}$ - distance $\Delta \mathrm{s}$ - distance difference, $\theta$ - angle of terrain slope, $\delta$ - deviation angle of the course.

\begin{tabular}{|c|c|c|c|c|c|c|}
\hline \multicolumn{7}{|c|}{$\begin{array}{l}\text { GEOMETRIC PARAMETERS OF THE RACING ROUTE (SLALOM) } \\
\text { NAOUSSA }\end{array}$} \\
\hline 1 & 2 & 3 & 4 & 5 & 6 & 7 \\
\hline GATES & $\Delta \mathrm{h} . \mathrm{i}$ & $\Delta s . \mathrm{i}$ & $\theta . i$ & $\theta . i$ & $\delta . i$ & V.gs* \\
\hline [i] & {$[\mathrm{m}]$} & {$[\mathrm{m}]$} & {$\left[{ }^{\circ}\right]$} & [\%] & {$\left[{ }^{\circ}\right]$} & Degree \\
\hline$\Sigma 10$ & 30,24 & 93,45 & & & & \\
\hline M10 & 3,02 & 9,35 & 19,9 & 36,1 & 25,8 & 18 \\
\hline SD & 0,66 & 3,34 & 4,51 & 8,65 & 11,7 & \\
\hline V & 0,22 & 0,36 & 0,23 & 0,24 & 0,5 & \\
\hline$\Sigma 58$ & 178,26 & 519,86 & & & & \\
\hline M58 & 3,02 & 8,81 & 19,97 & 36,51 & 30,7 & 14 \\
\hline SD & 1,24 & 3,13 & 5,97 & 11,42 & 18,8 & \\
\hline V & 0,41 & 0,36 & 0,30 & 0,31 & 0,6 & \\
\hline $\max$ & 5,68 & 17,61 & 32 & 62 & 88,1 & \\
\hline $\min$ & 0,01 & 0,73 & 1 & 2 & 4,4 & \\
\hline CORRELATIONS: & & V.gs-Ms & V.g-M $\theta$ & & V.gs-M $\delta$ & \\
\hline r 10: & & 0,34 & $-0,45$ & & $-0,86$ & \\
\hline r 58: & & 0,15 & $-0,52$ & & $-0,29$ & \\
\hline
\end{tabular}

*Slalom geometry factor: V.gs $=[\mathrm{Ms} /(\mathrm{M} \theta \times \mathrm{M} \delta)] \times 1000$ 


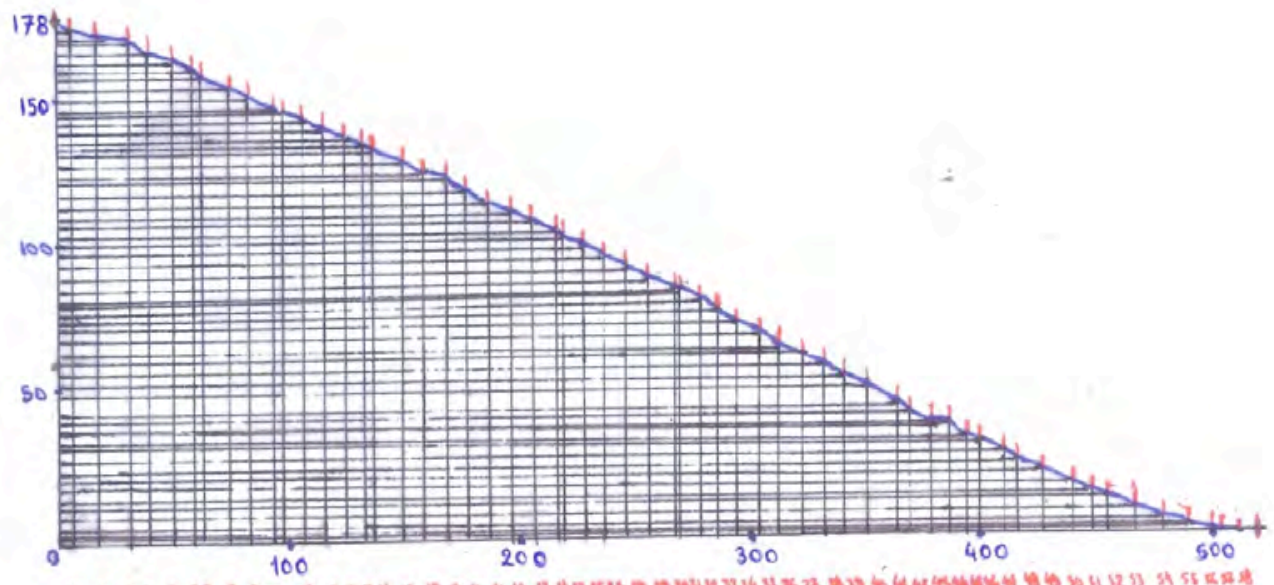

Figure 2. The side-view (Profile) of the entire slalom route in the ski resort "Tria - Pente Pigadia" (Naoussa).

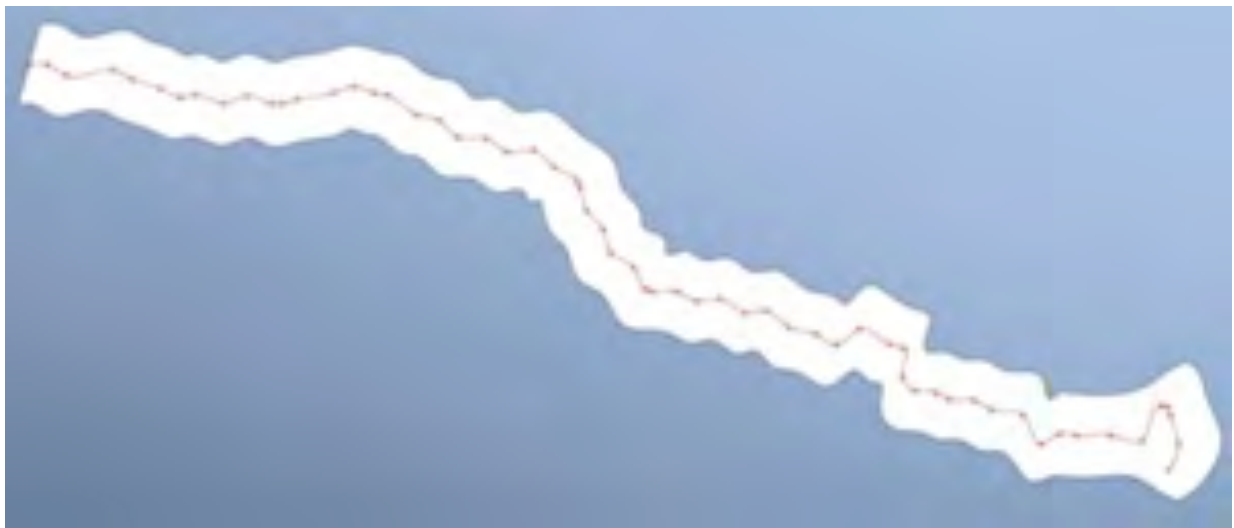

Figure 3. The top-view of the entire slalom route in Naoussa.

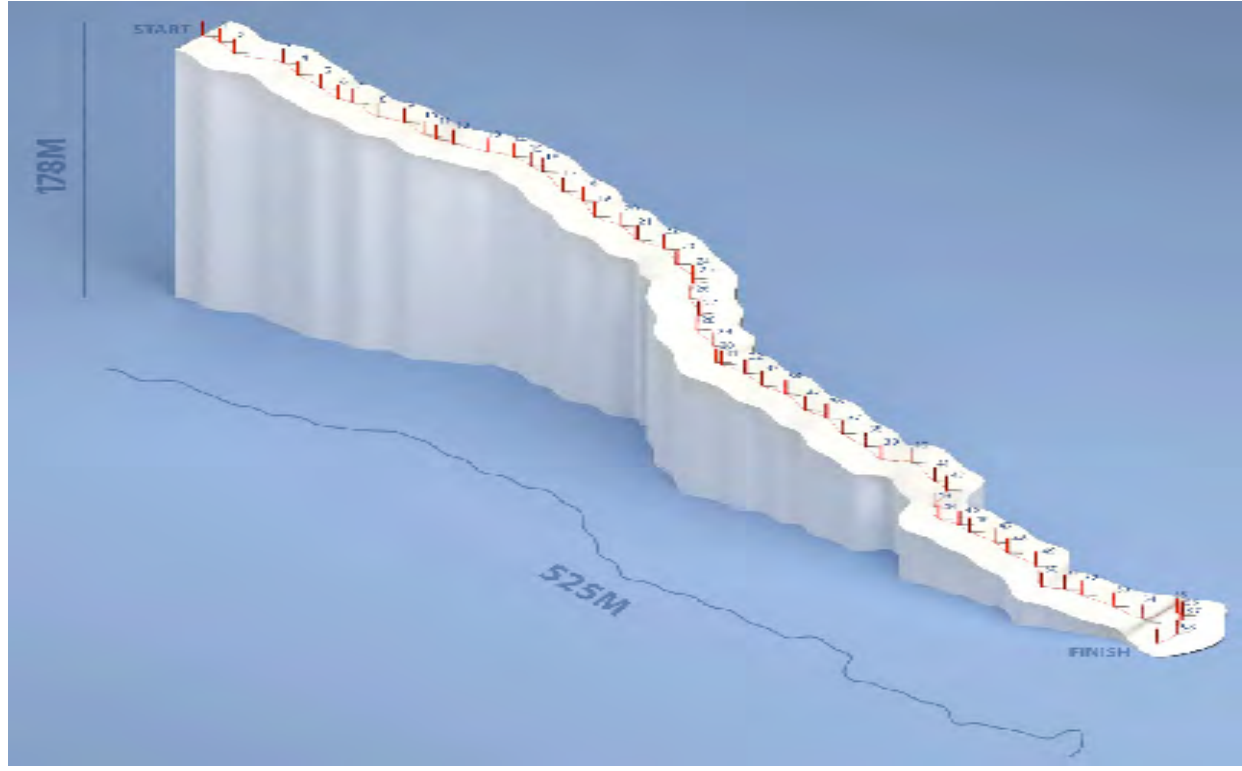

Figure 4. The three-dimensional form of the route with 58 slalom gates in Naoussa.

The slalom geometrical coefficient can be used to identify the key data of the slalom after the route engraving, which means that the quality characteristics with the interpretation "fast" or "slow" race track can be replaced with quantitative characteristics by using the average value of the slalom geometrical coefficient: $\mathrm{V} . \mathrm{gs}=[\mathrm{Ms} /(\mathrm{M} \theta \mathrm{x} \mathrm{M} \delta)] \times 1000[6]$.

The aggregated results of the geometric parameters and the slalom geometrical coefficient are depicted in Table 1. 
The slalom after the route engraving in Naoussa had the following geometrical parameters' average values:

$$
\mathrm{s}=8,81 \mathrm{~m}, \theta=19,97^{\circ}, \delta=30,72^{\circ} \text {, }
$$

while the first part of 10 gates had the following corresponding values:

$$
\mathrm{s}=9,35 \mathrm{~m}, \theta=19,90^{\circ}, \delta=25,76^{\circ} .
$$

The first part, comprised of 10 gates, was "faster" (V.gs $=18$ degrees) than the total slalom course in Naoussa with 58 gates ( $\mathrm{V} . g s=14$ degrees). The correlation coefficient (r) between the terrain slope $(\theta)$ and the coefficient of geometry (V.gs) was significant, at a statistical significance level of $p<0,05$. The value was $r=-0,52$ for 58 gates and 0,45 for 10 gates, which means with a negative sign that as the angle of inclination of the ground decreases, both the geometry coefficient increases, that is, the "speed of the track" with coincidence and the degree of difficulty of the track.

Also, the correlation coefficient ( $\mathrm{r}$ ) between the angular deviation of the gate $(\delta)$ and the geometry factor (V.gs) was $-0,29$ for 58 gates and $-0,86$ for 10 gates, meaning that as the angular deviation of the course decreases, the geometry factor increases and consequently so does the difficulty degree of the track. Finally, the distances between gates did not affect the difficulty degree of the track, because there wasn't a significant correlation between them.

\section{Discussion}

The characteristics of the slalom course:

The International Ski Federation - FIS presented the same homologated (certified) slalom and giant slalom course "Aristotle". The Archive of the ski club EOS Naoussa (1990) presented the survey data, which were measured in conditions without snow and without gates every $100-150 \mathrm{~m}[6,28]$. In the present research, the survey data were applied to racing conditions with snow and gates. The rating of the slalom coefficient geometry will be comparable with rating values of other slaloms at other tracks, given the condition that the coefficient measurement dataV.gs will be obtained from research on better athletes. Based on the analysis of the present research and of Giovanis' research [6] we can distinguish three types of slalom parts.

Type A - is the difficult segment, which is characterized by the great length of the segment, with a low terrain slope and a medium angle deviation of the course.

Type B- is the very difficult segment, in which we have combinations of gates, such as: hairpin, vertical or "banana”, where two or more gates (segments) are passed with a single turn and then we approach the gate with a big course deviation angle.

Type C - is the dangerous segment, which is characterized by the great length of the segment, with a steep terrain slope and a small course deviation angle.

Experienced coaches, "engravers" are engaged with the tracing of slalom. Their knowledge is based on a broad comprehension of the sport and a great practical experience. As it happens, however, the "engravers" is not able to trace the following gates with precision, as he would wish: he encounters "trap" gates or deviations from the exemplary trace as per regulation.

Possibilities to apply the results of research in practice:

Based on the results of the research, we can propose improvements to the regulations in order to make sailings safer by presenting the slalom geometry on specially formatted maps of the route. Topographic snow measurements in racing conditions (Figure 2-5) have the potential for a short, reliable and accurate measurement of slalom geometry parameters compared to recently certified (homologated) measurements on dry ground in non-snow conditions and without the gates. The geometric parameters and the manner that measurements can be used to organize matches, to inform coaches and athletes eg with special maps (eg. profile, plan view of the route and the three-dimensional form of slalom) and the preparation

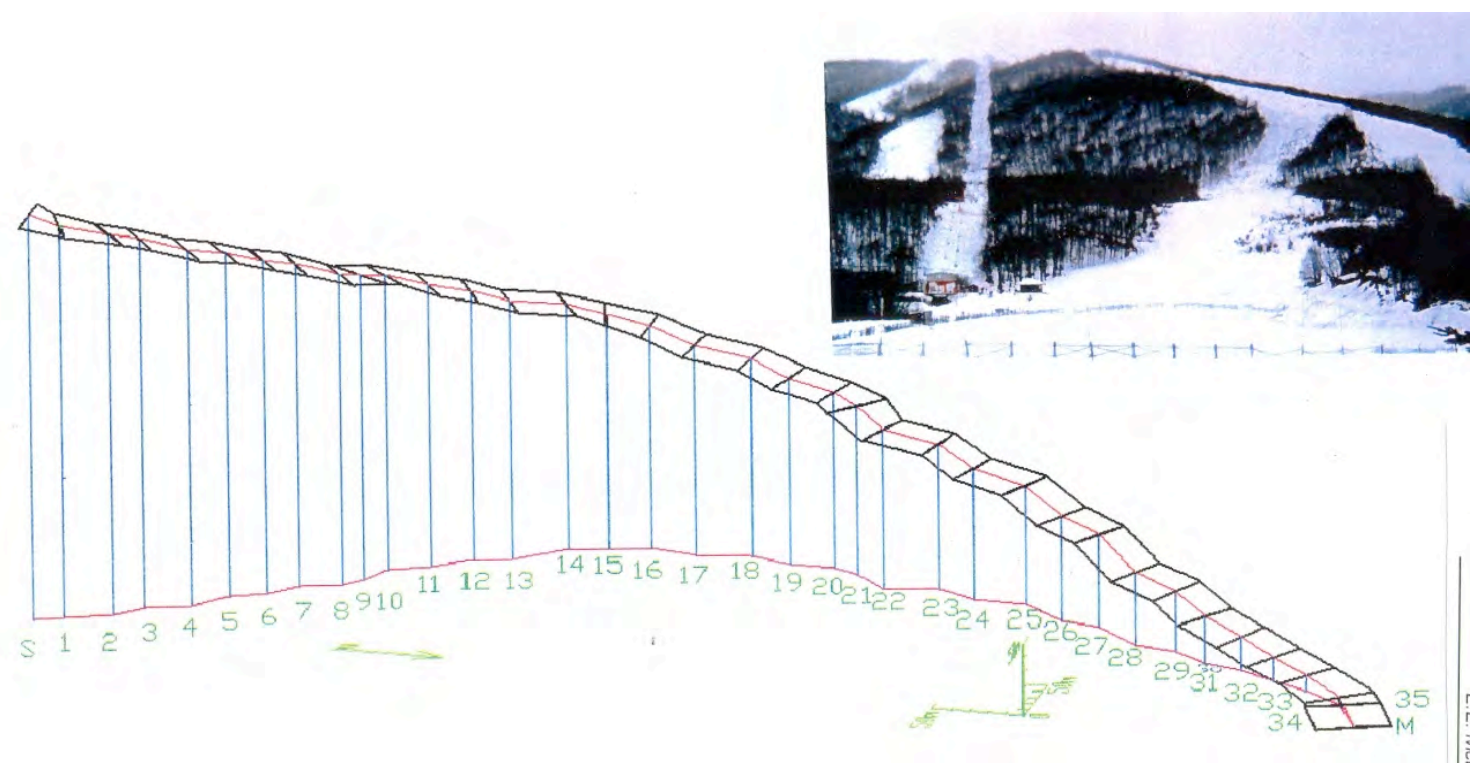

Figure 5. Topographic shape of the giant slalom course in racing conditions on snow and 35 gates in Naussa [6]. 
of racing tracks. The fast measurement of geometrical parameters $(\mathrm{h}, \mathrm{s}, \theta, \delta)$ enables display of the geometry in the electronic table and is the basis for achieving future kinematic parameters. Giovanis \& Erdmann [5] studied the problem of "engravers" route in Alpine skiing in order to remove the exterior gates of slalom and leave only the interior turn gates. The aforementioned study increases the safety of skiers, e.g. during the fall of the athlete, impact with the exterior gate is avoided, the race track space in the ski resort is increased and the recognition and memorization of the traced course by the athletes is improved [29, 30].

Also the route is placed in a shorter time and it is spectacular racing course for the fans. Recently, the International Ski Federation announced changes to the regulations in the slalom events, in which they abandoned the exterior gates except the first and the last gate in the giant slalom, while in the slalom, combinations of gates remain.

\section{Conclusions and recommendations}

Based on this research we can conclude the following:

1) It is feasible to have the detailed project with side-view, top-view and three-dimensional form of the slalom given. It is also possible to "engravers" the track on the same day of the race, because with the help of technology measurements can be performed faster than with conventional instruments.

2) The relationship of the topographic speedometer with the environment and the morphology of the route is friendly. It is an easy to carry instrument, functional and effective in precision measurements.

3) The topographic speedometer does not affect the conventional tracing of the spontaneous slalom route, while it contributes significantly to the prevention of accidents and elimination of athletes by identifying the basic parameters of geometry from the start to the finish line.

4) The "speed" of the race route (the degree of slalom difficulty) can be controlled through the slalom geometric coefficient (V.gs).

5) The race organizers must apply the required measurements in order to obtain information about the slalom geometry and improve the race safety.

6) With the above criteria, it will be possible to compare the slaloms to each other and will be evaluated against age, level and safety.

\section{Conflict of interests}

The authors declare that there is no conflict of interests.

\section{References}

1. FIS. Memorandum for the Technical Delegate. Oberhofen, Switzerland: International Ski Federation; 2005.

2. Cotelli F, Cotelli M. Sci competizione. La tecnica delle tre discipline: slalom, gigante e discesa. [Ski competition. The technique of the three disciplines: slalom, giant and descent]. Milan: Longanesi R.C.; 1981. (In Italian)

3. Nachbauer W. Lienienführung und Druckverlauf bei Torlauf und Riesentorlauf. [Leading line and course of pressure in slalom and giant slalom]. AUSTRIA SKI, 1985;4(85):34-35. (In German)

4. Nachbauer W. Fahrlinie in Torlauf und Reisentorlauf. [Course line in slalom and giant slalom]. Leistungs sport, 1987; 17(6):17-21. (In German)

5. Erdmann WS, Giovanis V. Preliminary investigations of kinematics of a skier in giant slalom (in Polish). In: Mazurkiewicz S (ed.) Proceedings. All Polish Conference of Biomechanics. Krakow: B. Czech University, School of Physical Education; 1995. P. 57-62.

6. Giovanis V. Kinematics of slalom courses' runs in alpine skiing and problem of injuries. $\mathrm{PhD}$ [dissertation]. Cracow: University of Physical Education; 1998. (in Polish).

7. Henning E. Improvement of GPS accuracy for the tracking of human motion by the elimination of "Selective Availability" restrictions. In: Gerber $\mathrm{H}$, Müller $\mathrm{R}$ (ed). International Society of Biomechanics XVIIIth Congress. Zurich; Swiss Federal Institute of Technology; 2001. P. S10.

8. Aschenbrenner P. Kinematics of competitors' running on the course of alpine skiing giant slalom and its geometric parameters $\mathrm{PhD}$ [dissertation]. J. Sniadecki University of Physical Education, Gdansk; 2002. (in Polish).

9. Brodie M, Walmsley A, Page W. Force vector analysis of ski racing technique using fusion motion capture. In: Menzel H-J, Chagas MH (ed) 25th International Symposium on Biomechanics in Sports. Proceedings. Ouro Preto, MG,
Federal University of Minas Gerais, Belo Horizonte, MG; 2007. P. 71-74.

10.Brodie M, Walmsley A, Page W. Fusion motion capture: a prototype system using inertial measurement units and GPS for the biomechanical analysis of ski racing. Sports Technol. 2008, 1:1:17-28.

11.Hasler M, Abwerzger G, Hofmann-Wellenhof B, Nachbauer W. A kinematic carrier phase GPS for biomechanical analyses. In: Schena F (ed). Book of Abstracts of the 2nd International Congress "Mountain, Sport \& Health". Rovereto; Interuniversity Research Center in Bioengineering and Motor Science; 2007. P 41.

12.Seifriz F, Mester J, Krämer A, Roth R. The use of GPS for continuous measurement of kinematic data and for the validation of a model in alpine skiing. International Journal of Computer Science in Sport, 2009;1:62-63.

13.Skaloud J, Limpach P. Synergy of CP-DGPS, Accelerometry and Magnetic Sensors for Precise Trajectography in Ski Racing. ION Press GPS/GNSS, 2003;3:9-12.

14.Skaloud J, Gontran H, Merminod B. GSM-Distributed RTK for precise analysis of speed skiing. 8th European Navigation Conference GNSS 2004. Rotterdam; 2011. P.120.

15.Waegli A, Skaloud J. Assessment of GPS/MEMS-IMU Integration Performance in Ski Racing. Presented at European Navigation Congress ENC-GNSS, Geneva; 2011. P. 40.

16.Pozzo R, Canclini A, Casasola S, Ciro D, Cotelli Ch, Baroni G. 3-D kinematic and kinetic analysis of G-slalom at Valbadia World Cup Race in 2002. In: Schena F (ed). International Congress "Mountain and Sport. Updating Study and Research from Laboratory to Field”, Programme and Book of Abstracts. Rovereto: Interuniversity Research Center in Bioengineering and Motor Science; 2005. P. 48.

17.Supej M. A step forward in 3D measurements in alpine skiing: a combination of an inertial suit and DGPS technology. In: Müller E, Lindinger S, Stöggl T, Fastenbauer V. (ed). 
4th International Congress on Science and Skiing 2007, Salzburg: University of Salzburg; 2007. P. 100.

18.Supej M. 3D measurements of alpine skiing with an inertial sensor motion capture suit and GNSS RTK system. Sports Sciences, 2010, 28(7):759-769.

19.Giovanis V, Erdmann WS. Problem of outer slalom poles in alpine skiing. Gdansk: J. Sniadecki University, School of Physical Education; 1996. Report No.:1996-01. (in Polish)

20.Giovanis V, Giovani Ch, Kotrotsios S, Lapszo J. Review of methods of simulation in skiing. Physical Education-SportHealth. 2010; 25:18-38 (in Greek).

21.Twardokens GR. Brachistochrone (i.e. shortest time) in skiing descents. In: Nosek M, Sojka D, Morrison WE, Susanka P (ed.). Proceedings of the VIIIth International Symposium of the Society of Biomechanics in Sports, Praha: Conex Company; 1990. P. 205-209.

22.Erdmann WS, Suchanowski A, Aschenbrenner P. Geometry and running of the alpine ski FIS World Cup giant slalom. Part one - geometry. In: Hong Y., Johns D. P. (ed). Proceedings, XVIII Symposium of the International Society of Biomechanics in Sports, The Chinese University of Hong Kong, 2000; 2: 637-641.

23.Erdmann WS, Giovanis V, Aschenbrenner P, Suchanowski A. Geometry and Running of the Alpine Ski FIS World Cup Giant Slalom, Part two - Velosity. In: Blackwell J.R. (ed). XIX International Symposium on Biomechanics in Sports. University of San Francisco; 2001. P. 5.
24.Erdmann WS, Aschenbrenner P. Geometry and running of the alpine ski FIS World Cup giant slalom. Part 3: Velocity as a function of geometry. In: K. E. Gianikellis. Cáceres (ed). Proceedings of the Exit International Symposium on Biomechanics in Sports, Cancers, Spain, Univ. de Extremadura. Servicio de; 2002. P. 101.

25.Erdmann WS, Giovanis V, Aschenbrenner P, Kyriakis V, Suchanowski A. Methods for acquiring data on terrain geomorphology, course geometry and kinematics of competitors' runs in alpine skiing: a historical review. Acta of Bioengineering and Biomechanics. 2017; 19(1):69-79.

26.Giovanis V. Techniki tis chionodromias [Skiing technique]. Athens; 2006 (in Greek).

27.Giovanis V. Proponitiki sti chionodromia katavaseon [Coaching in Alpine skiing]. Athens; 2008. (in Greek).

28.EOS Naoussa-FIS. Hellenic Mountaineering Association. Ski Center - The data of the homologation track of slalom, giant slalom and super-giant slalom by the International Ski Federation (FIS). Topographic material of the route on dry ground “Aristotle” (Balcony) at 3-5 Pigadia (Naoussa), Greece; 1990.

29.Erdmann WS, Giovanis V. Incidents in alpine skiing giant slalom. In: Riehle H. J., Vieten M. M. (ed.) Proceedings, XVI Symposium of the International Symposium on Biomechanics in Sports, Konstanz: University of Konstanz; 1998. P. 311312.

30.FIS. Injury Prevention. Oberhofen, Switzerland: International Ski Federation; 2011.

\section{Information about the authors:}

GiovanisV.F. (Corresponding author); PhD; http://orcid.org/0000-0003-2511-8286; vgiovan@phed.uoa.gr; School of Physical Education and Sport Science, National and Kapodistrian University of Athens; 41 Ethnikis Antistassis Str., Daphne 17237, Athens, Greece.

Yiaghis F.A.; http://orcid.org/0000-0002-9524-7238; bluals@hotmail.com.gr; School of Physical Education and Sport Science, National and Kapodistrian University of Athens; 41 Ethnikis Antistassis Str., Daphne 17237, Athens, Greece.

Vasileiou P.V.; http://orcid.org/0000-0003-2823-6093; panvas265@gmail.com; School of Physical Education and Sport Science, National and Kapodistrian University of Athens; 41 Ethnikis Antistassis Str., Daphne 17237, Athens, Greece.

Cite this article as: Giovanis VF, Yiaghis FA, Vasileiou PV. Topographic recording of the Slalom racing route in snow. Pedagogics, psychology, medical-biological problems of physical training and sports, 2018;22(1):4-10. doi:10.15561/18189172.2018.0101

The electronic version of this article is the complete one and can be found online at: http://www.sportpedagogy.org.ua/index.php/PPS/issue/archive

This is an Open Access article distributed under the terms of the Creative Commons Attribution License, which permits unrestricted use, distribution, and reproduction in any medium, provided the original work is properly cited (http://creativecommons.org/licenses/by/4.0/deed.en).

Received: 03.11.2017

Accepted: 02.12.2017; Published: 26.02.2018 